\title{
PEMANFAATAN PERLIT YANG TELAH DIMODIFIKASI UNTUK AMOBILISASI ENZIM BROMELAIN
}

\author{
Elida Mardiah \\ Jurusan Kimia FMIPA Unand Padang
}

\begin{abstract}
Amobilization of bromelaine enzyme extracted from ananas fruit (Ananas comusus) acetone has been done. Modified perlite in the amino silica phosphat (ASP) is used as matrix amobilization. The protein content has determined by Lowry method, while enzyme activity were determined by Anson method caseine as substrate. It native enzyme specific activity was 0.1281 unit $/ \mathrm{mg}$ with konsentration $20000 \mathrm{ppm}, \mathrm{pH} 7.0$, incubation time 35 minutes, and temperature $40^{\circ} \mathrm{C}$. Amobil

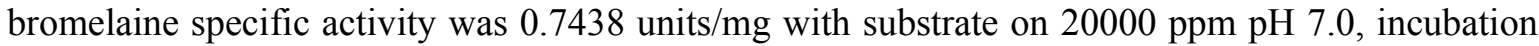
time 30 minutes and temperature $37^{\circ} \mathrm{C}$. This bromelaine enzymes activity was increased six times than native enzim and showed the activity for several repeatation.
\end{abstract}

Keywords: perlit, enzim bromelain, amobilization

\section{DAFTAR PUSTAKA}

1. H. D., Belitz, Food Chemistry, SpringerVerlag, Germany, 1987.

2. An Introduction About Immobilized Enzymes, http:/www.google.com/ Immobilized.html.

3. B. F. Amstrong, Biochemistry, $2^{\text {nd }} e d$, Oxford University Press, New York, 1983.

4. Proteolytic Enzyme For Food Application, http:/www.valleyenzyme.com/enzyme/brom elain/html.

5. T. Murachi and M. Yasui, Biochemistry, 4, 1965, 2275.

6. Bromelain Pineapple Steams, http:/www.calzyme.com/ calzyme laboratories, Inc.

7. H. Sarno, End Perlit di Indonesia, Direktorat Jendral Sumber Daya Mineral, Jakarta, 1993, 1 - 22.

8. N. S. Wang, Enzyme Immobilization by Gel Entrapment, Department of Chemical Enginering, University of Maryland.

9. Methods of Immobilization, http:/www.google.com/entrapped/methods. html.

10. Hindi-Tamelikecht, Analytic and Immunologic Characterization of Chicpea (Cicer arietinum) Protein Hyrolytes Obtained by Bromelain and
Alphachimotrypsin, J. Agric. Food Chem., 45: 4758-4762, (1997).

11. P. Arbinto, Biokimia Konsep-Konsep Dasar, Departemen Pendidikan dan Kebudayaan, Departemen Pendidikan Tinggi, Bandung, 1996.

12. C. Q. Claret, Gel Immobilization Protein Phosphatase 2A From Yarrowia Lipolytica Dephosphorylates Phosvitin and Modifies its Functional Properties, J.Agric Food Chem., 45, 2899-2906, (1997).

13. S. Sun, Immobilization and Characterization of Galactosidase From The Plant Gram Chicken Bean (Cicer arietenium). Evaluation of its Enzymatic Actions in the Hydrolysis of Lactose, $J$. Agric. Food Chem., 47: 819-823, (1997).

14. J. Willian, An Introduction to General Organic and Byological Chemistry, Prentice-Hall, New Jersey, USA, 579-581.

15. T. Kawai, Conversion of Dextan to Cycloisomaltooligosacharides Using an Enzyme-Immobilized Porous HollowFiber Membrane, J. Agric. Food Chem., 50: 1073-1076, (2002).

16. I. Danishefsky, Biochemistry for Medical Sciences, Little, Brown and Company, Boston, 1980.

17. H. Et. Sherif, Advantages of Using NonIsotermal Bioreactors in Agricultural Waste Water Treatment by Means of 
Immobilized Urease, Study on the Influence of Spacer Length and Immobilized Methods, J. Agric. Food Chem., 50: 2802-2811, (2002).

18. F. G. Winarno, Enzim Pangan, PT. Gramedia Pustaka Utama, Jakarta, 1995, 75-76.

19. D. Darwis, Peran Industri Perlit Dalam Era Pembangunan, Makalah yang
Disampaikan Pada Seminar Nasional Kimia dalam Industri dan Lingkungan, Ikahimki,Himka,FMIPA-UA, Padang, April 1998.

20. PPNF Article, http:/www.priopottenger.org/articles/pinneaple.html.

21. Soeparno, Ilmu dan Teknologi daging, Gadjah Mada Press, Yogyakarta, 1994. 